\title{
Impact of insulation thicknesses of several types of thermal insulator on energy cost with respect to different climate zones in Morocco
}

\author{
Ayoub Gounni ${ }^{*}$, Mohamed Tahar Mabrouk ${ }^{2}$, Abdelhamid Kheiri ${ }^{2}$, Mustapha El Alami ${ }^{1}$ \\ ${ }^{1}$ LPMMAT, Faculté des sciences Ain Chock, Université Hassan II, Km8 Route d'el Jadida B.P 5366 Maarif Casablanca \\ 20100 Maroc. \\ ${ }^{2}$ Université de Lorraine, Lemta, UMR CNRS 7563, 2 avenue de la Forêt de Haye, Vandœuvre-lès-Nancy, F-54500. France.
}

\begin{abstract}
In Morocco the thermal insulation of buildings envelop was not a common practice until it becomes obligatory since 2015 to meet the requirements of the Moroccan construction thermal regulation (RTCM) depending on six climate zones. The aim of this paper is to determine the optimum thickness of expanded polystyrene (EPS) and rock wool (RW) of walls constructed of brick for different Moroccan climate zones: Agadir (first zone), Tanger (second zone), Fes (third zone), Ifrane (fourth zone), Marrakech (fifth zone), Errachidia (sixth zone). A numerical model of a multilayered wall is developed to compute the annual heating and cooling loads. These loads are used as input to life cycle cost analysis using the energy and insulation costs. The liquefied petroleum gas (LPG) and electricity are used as energy source, respectively, for heating and cooling. For each case, the calculation is carried out for annual heating and cooling loads and total cost including insulation and energy costs. Results show that the optimum thermal insulation depends on climate zones and insulation types. The lowest value of energy savings is obtained for climate zone 1 which are 289.55 and $300.55 \mathrm{dh} / \mathrm{m}$ respectively for EPS and RW.
\end{abstract}

\section{Introduction}

The energy demands of buildings are increasing on account of their inhabitants' thermal comfort requests. The external components of a building such as external walls are responsible of major part of heat loss through the building envelope. Using thermal insulation can reduce the rate of heat transmission across these building elements [1]. With the implementation of Moroccan construction thermal regulation (RTCM), thermal insulation becomes one of the most important current topics in energy economy in Morocco [2]. It is well known that using thermal insulation in building reduces the rate of heat transmission, which translate to energy savings but at a higher initial cost. In this framework, it is crucial to identify an optimum insulation thickness at which the total cost, including the cost of insulation material and cost of energy consumption over the lifetime of the building, is minimum [3]. There are many studies dealing with the optimal insulation thicknesses in the literature [3]-[5] but a few for the Moroccan case. The first attempt to determine the optimal insulation thickness under the climatic conditions of Morocco is done by Idchabani et al. [6]. In their work, the optimum thickness of expanded polystyrene, polyurethane and cork is determined based on life cycle cost analysis. Their results indicate that optimum insulation thickness depends on selected insulation materials, the source of energy and its price. However, the method used to compute the heating and cooling loads is based on degree-days concept which is a simple and crude model that have been mainly developed in order to estimate the heat transmission loads under static conditions [7].

In this work, the cooling and heating loads are calculated by using an implicit finite volume method under dynamic thermal conditions for a south-facing wall at the climatic conditions of six climate zones of Morocco. The optimum insulation thicknesses and energy savings are calculated by considering both cooling and heating loads, and compared for different climate zones. The calculation is done for two insulation materials: the expanded polystyrene and the Rock wool. Electricity and liquefied petroleum gas are considered as energy sources, respectively for cooling and heating.

\section{Mathematical formulation}

The transient heat conduction through a multilayer wall, which consists of $\mathrm{n}$ layers of different materials and thicknesses, is governed by the following equation:

$$
\frac{\partial^{2} T_{j}}{\partial x^{2}}=\frac{1}{\alpha_{j}} \frac{\partial T_{j}}{\partial t} \quad \text { For } \mathrm{j}=1,2, \ldots, \mathrm{n}
$$

\footnotetext{
* Corresponding author: gounni.ayoub@gmail.com
} 
It is supposed that each material is homogeneous without internal heat generation and the thermal properties are constant in respect to the temperature. An initial arbitrary uniform temperature field is assumed. The thermal contact between successive layers is assumed to be perfect. Convenient radiative and convective conditions are put on the inside and the outside surfaces. The developed model is successfully validated against a previous work done by Daouas et al.[8].

\section{The structure of the external wall}

A typical building wall constructed of brick is considered as shown in Fig. 1 and the thermophysical properties of its layers are shown in Table 2. The investigation is carried out for a south-facing wall at the climatic conditions of the six Moroccan climate zones as presented in table 2. The hourly solar radiation flux on the wall is calculated by using Perez model [9]. Outdoor air temperature of the six climate zones is shown in Fig.2. The constant indoor air temperatures selected for the representative day of each month are given in Table 3. The solar absorptivity of opaque wall is selected to be equal to 0.4 and the combined heat transfer coefficients at the indoor and the outdoor wall surfaces are taken to be 9 and $22 \mathrm{~W} / \mathrm{m} 2 \mathrm{~K}$, respectively [11], [12].

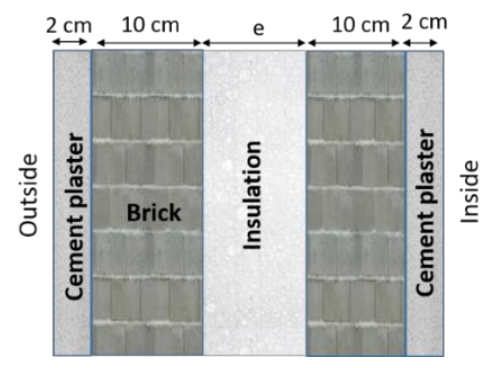

Fig. 1. Construction of the typical wall.

Table 1. Thermo-physical properties of construction materials [8], [10].

\begin{tabular}{|c|c|c|}
\hline Layers & $\begin{array}{c}\text { Conductivity, } \\
\mathbf{k}(\mathbf{W m - 1 . K - 1 )}\end{array}$ & $\begin{array}{c}\text { Diffusivity, } \boldsymbol{\alpha} \\
\left(\mathbf{m}^{\mathbf{2}} \mathbf{/ s}\right)\end{array}$ \\
\hline Cement plaster & 0.72 & $4.6 \times 10-7$ \\
\hline Brick & 0.69 & $5.13 \times 10-7$ \\
\hline $\begin{array}{c}\text { Expanded polystyrene } \\
\text { (EPS) }\end{array}$ & 0.037 & $1.01 \times 10-6$ \\
\hline Rock wool (RW) & 0.047 & $2.67 \times 10-6$ \\
\hline
\end{tabular}

Table 2. Goographical parameters of used Moroccan climate zones.

\begin{tabular}{|c|c|c|c|}
\hline Zones & $\begin{array}{c}\text { Latitude } \\
\left({ }^{\circ} \mathbf{N}\right)\end{array}$ & $\begin{array}{c}\text { Longitude } \\
\left({ }^{\circ} \mathbf{W}\right)\end{array}$ & $\begin{array}{c}\text { Altitude } \\
(\mathbf{m})\end{array}$ \\
\hline Zone1 (Agadir) & 30,383 & 9,567 & 56 \\
\hline $\begin{array}{c}\text { Zone2 } \\
\text { (TANGER) }\end{array}$ & 35,58 & 5,33 & 126 \\
\hline Zone3 (Fez) & 34.01 & 5.00 & 426 \\
\hline Zone4 (Ifrane) & 33.5 & 5.167 & 1305 \\
\hline $\begin{array}{c}\text { Zone5 } \\
\text { Marrakech) }\end{array}$ & 31.56 & 7.95 & 527 \\
\hline $\begin{array}{c}\text { Zone6 ( } \\
\text { Ouarzazate) }\end{array}$ & 30.93 & 6.93 & 1134 \\
\hline
\end{tabular}

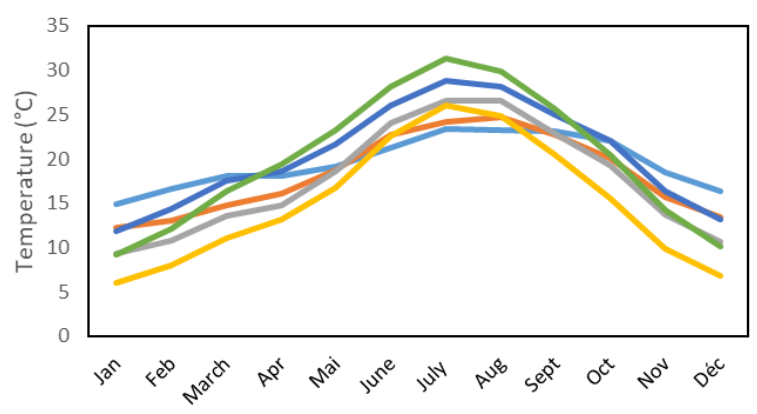

Zone 1 -Zone 2 -Zone 3 -Zone 4 Zone 5 -Zone 6

Fig.2. Ambient temperature of the six climate zones.

\section{Results and discussion 4.1 Optimum insulation thickness}

The optimum insulation thickness is the thickness at which the total cost is a minimum. This total cost takes into account the cost of energy required to cover the annual heating and cooling loads, the cost of insulation materials and the present value of the energy consumption cost over the lifetime of the building including the inflation rate and the discount rate. The parameters required in the calculation are presented in table 3 .

Fig.3. shows variation of cost with respect to the insulation thickness for two different insulation materials in the brick wall. It is shown that while the energy cost decreases with increasing insulation thickness, the insulation cost increases linearly with insulation thickness. The total cost is the sum of insulation and energy costs. The insulation thickness for which the total cost is minimum is considered as the optimum insulation thickness. It is seen that the total cost related to the climate zones 1 and 2 have the same trend; also, the total cost related to the climate zones 3-6 have the same trend. This occurs because these climate zones have practically the same climatic conditions. Based on table 4, the thermal insulation RW has the lowest value of optimum thickness for all climate zones compared to EPS; due to its lowest cost $\left(800 \mathrm{MAD} / \mathrm{m}^{2}\right)$ compared to the cost of EPS $\left(1200 \mathrm{MAD} / \mathrm{m}^{2}\right)$. It is also concluded from the table 4 that the zone 1 has the lowest value of optimum insulation thickness, 0.056 and $0.078 \mathrm{~m}$, respectively for EPS and RW.

Table 3. Computing parameters (Notice that, January 2017, roughly $1 \mathrm{MAD}=0.11 \mathrm{USD}$ )

\begin{tabular}{|c|c|}
\hline Parameter & Value \\
\hline GPL (for heating) & \\
\hline Cost, $\mathrm{CF}$ & $3.33 \mathrm{MAD} / \mathrm{kg}[6]$ \\
\hline heating value, $\mathrm{Hu}$ & $12.66 \mathrm{kWh} / \mathrm{kg}$ \\
\hline$\eta$ & $90 \%$ \\
\hline Electricity (for cooling) & \\
\hline Cost, CE & $0.9010 \mathrm{MAD} / \mathrm{kWh}$ \\
\hline Coefficient of performance, COP & 3 \\
\hline Insulation materials & \\
\hline Polystyrene (EPS) cost, Ci & $1200 \mathrm{MAD} / \mathrm{m} 3$ \\
\hline Rock wool (RW) cost, Ci & $800 \mathrm{MAD} / \mathrm{m} 3$ \\
\hline Interest rate, $\mathrm{i}$ & $1.6 \%$ \\
\hline Inflation rate, $\mathrm{g}$ & $2.5 \%$ \\
\hline
\end{tabular}



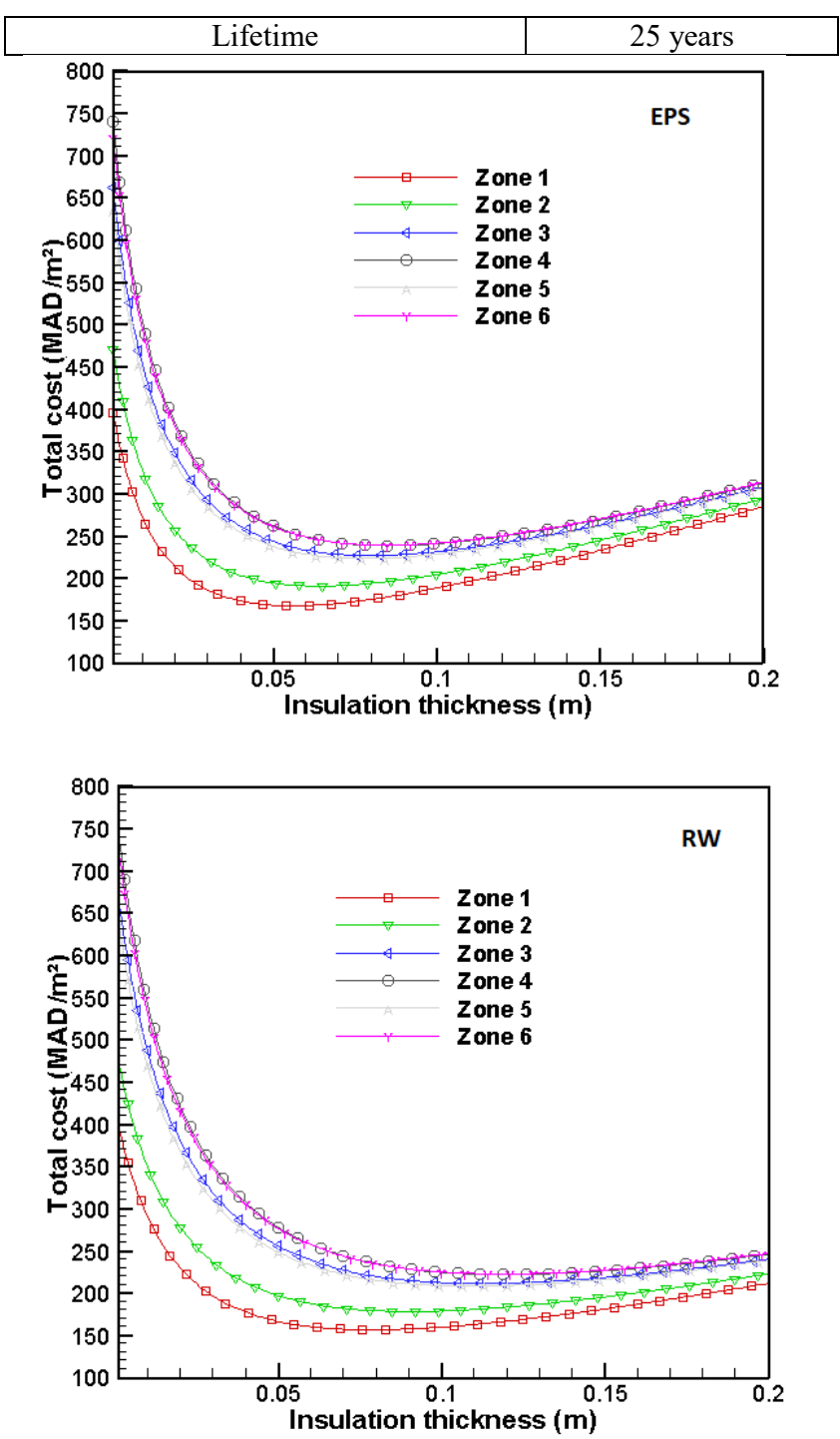

Fig.3. Variation of cost with insulation thickness for six Moroccan climate zones.

\subsection{Energy savings}

The energy saving is defined as the difference between total costs of heating and cooling with and without wall insulation. This total cost takes into account the cost of energy required to cover the annual heating and cooling loads, the cost of insulation materials and the present value of the energy consumption cost over the lifetime of the building including the inflation rate and the discount rate. Fig. 4 shows the effect of insulation thickness on energy saving for two different insulation materials and six climate zones. For all insulation types, as insulation thickness increases, energy saving increases until it reaches its maximum value at the optimum insulation thickness and then decreases. It is seen that the lowest value of energy savings is obtained for climate zone 1 while the highest energy savings are obtained for climate zone 4 . Table 4 presents the energy savings at optimum insulation thickness. It is concluded that the RW offers a high energy saving compared to EPS.
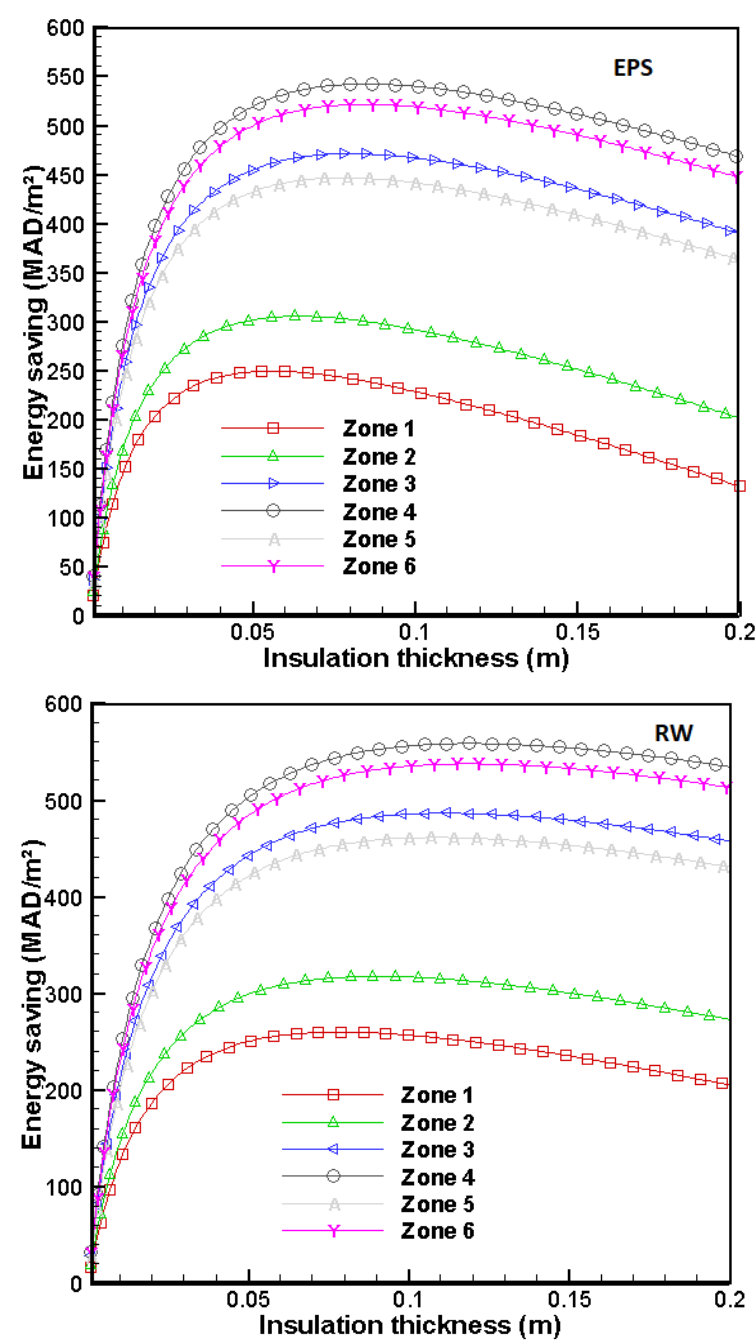

Fig.4. Variation of energy savings versus insulation thickness for six Moroccan climate zones.

Table 4. Optimum thickness of two types of thermal insulation for six climate zones.

\begin{tabular}{|c|c|c|c|c|}
\hline & \multicolumn{2}{|l|}{$\begin{array}{l}\text { Optimum } \\
\text { insulation } \\
\text { thickness (m) }\end{array}$} & \multicolumn{2}{l|}{$\begin{array}{l}\text { Energy saving at } \\
\text { optimum thickness } \\
\text { (MAD/m }\end{array}$} \\
\hline Zones & EPS & RW & EPS & RW \\
\hline Zone 1 & 0.056 & 0.078 & 248.97 & 259.63 \\
\hline Zone 2 & 0.064 & 0.09 & 304.84 & 317.17 \\
\hline Zone 3 & 0.08 & 0.112 & 470.55 & 485.83 \\
\hline Zone 4 & 0.085 & 0.119 & 541.53 & 557.91 \\
\hline Zone 5 & 0.078 & 0.109 & 445.92 & 460.82 \\
\hline Zone 6 & 0.085 & 0.119 & 520.67 & 536.91 \\
\hline
\end{tabular}

\section{Conclusion}

This study deals with the optimum insulation thickness of building walls under dynamic thermal conditions. The investigation is focused on the Moroccan climate and was carried out by using an implicit finite volume method for multilayer walls. The optimum insulation thicknesses and energy savings are determined over lifetime of 25 years of the building. Results show that the optimum thickness for EPS and RW varies respectively between 0.056 and $0.085 \mathrm{~m}$ and between 0.078 and $0.119 \mathrm{~m}$. The lowest value of energy savings 
is obtained for climate zone 1 which are 248.97 and 259.63 $\mathrm{MAD} / \mathrm{m}^{2}$ respectively for EPS and RW. It is concluded that the optimum thickness of insulation depends on climate zones and on thermal insulation material.

\section{References}

[1] R.Freire, G.Oliveria, N.Mendes, Energy Build, 40, 1353-65 (2008)

[2] RTCM. Moroccan Thermal Regulation for Constructions. (2015) (Available in: http://www.aderee.ma/index.php/fr/expertise/efficaciteenergetiquel batiment Accessed since Junuary the 1st).

[3] S. Al-Sanea. F. Zedan, International Journal of Ambient Energy 23, 3 (2002).

[4] S. Al-Sanea, F.Zedan, and S. AlAjlan, APPL ENERG, 82 (4), 313-330, (2005)

[5] A. BOLATTÜRK, Appl. Therm. Eng., 26 (11), 1301-1309, (2006)

[6] R.IDCHABANI, A.KHYAD and M. EL GANAOUI, Energy Procedia, 139, 117-121 ( 2017)

[7] M. OZEL, Appl. Therm. Eng., 31 (17) 3854-3863. (2011)

[8] N.Daouas, Z.Hassen and H. Aissia. Appl. Therm. Eng., 30, 319-326 (2010)

[9] R. Perez. P. Ineichen. R. Seals. J. Michalsky and R. Stewart, Solar Energy. 44 (5) 271 - 289 (1990)

[10] CSTB, Règles Th-U Détermination des caractéristiques thermiques «utiles» des matériaux.

[11] Ö.Kaska. R. Yumrutas, Energy 33 (2008)

[12] Ö.Kaska. R. Yumrutas, APPL ENERG 86 (2009) 